\title{
Comparison of the Remineralizing Effect of Brushing with Aloe vera versus Fluoride Toothpaste
}

\author{
Teresa Al Haddad ${ }^{1} \quad$ Elie Khoury ${ }^{2} \quad$ Nada Farhat Mchayleh ${ }^{1}$ \\ ${ }^{1}$ Department of Pediatric Dentistry, Saint Joseph University of \\ Beirut, Beirut, Lebanon \\ ${ }^{2}$ Department of Orthodontics, Saint Joseph University of Beirut, \\ Beirut, Lebanon
}

\begin{abstract}
Address for correspondence Elie Khoury, DDS, MSc, PhD, Department of Orthodontics, Saint Joseph University of Beirut, B.P. 11-5076 - Riad El Solh, Beirut, Lebanon (e-mail: elie.khoury@usj.edu.lb).
\end{abstract}

Abstract

Keywords
- Aloe vera
- remineralization
- fluoride
- toothpaste
- SEM-EDX
- prevention
- dentistry

Objectives The aim of the present in vitro study is to compare the remineralization brushing effect of three toothpastes and Aloe vera (AV) gel.

Materials and Methods Forty sound extracted teeth were placed in a demineralizing solution for 4 days and randomly assigned to four groups: group A: 1,450-ppm fluoride toothpaste; group B: AV nonfluoridated toothpaste; group C: AV 1,000-ppm fluoridated toothpaste; and group D: AV gel. A 3-minute $\mathrm{pH}$ cycling was performed twice a day for each group for 12 days. Specimens were analyzed before and after by scanning electron microscope-energy dispersive X-ray.

Statistical Analysis The outcomes were analyzed by Kolmogorov-Smirnov's tests, repeated-measures analyses of variance followed by univariate analyses, and Bonferroni's multiple comparisons tests to compare the calcium-to-phosphorus (Ca:P) ratio within time among toothpaste groups.

Results Following remineralization, the $C a: P$ ratio increased in all groups. The difference of the Ca:P ratio was not significant between groups $C, D$, and $A$. The mean ratio was significantly lower in group B ( $p$-value $=0.026)$.

Conclusions The $\mathrm{AV}$ gel demonstrated a remineralization capacity equal to that of the 1,450-ppm fluoride toothpaste. In contrast, fluoride-free AV toothpaste showed a lower remineralization efficiency. Further studies are required to understand its mechanism.

\section{Introduction}

Dental caries is a public health issue that affects a large number of people around the world. It is mainly caused by a dynamic process characterized by a succession of both alternating demineralization and remineralization periods. The lesion progresses when the demineralization favoring pathological factors such as fermentable carbohydrates, cariogenic bacteria, and salivary dysfunctions win over the protective factors such as antibacterial agents, remineralizing ions, and efficient saliva. ${ }^{1}$

Fluoride has been proven to reverse and prevent the carious process by inhibiting demineralization, enhancing remineralization, and considering its antibacterial properties. $^{2-6}$ Since the 1950 s, fluoride has been considered the gold standard in caries prevention. However, emerging epidemiological data show a worrying trend: Caries rate is stagnating or even increasing in some population groups notwithstanding the regular use of fluoride toothpastes in these countries..$^{7-10}$ In the era of holistic dentistry and after fluoride has been classified as a chemical neurotoxicant, some safety concerns arose regarding the use of highly concentrated fluoride products. ${ }^{11}$ More appropriate are the thriving concerns that children nowadays are exposed to fluoride from multiple sources, putting them at risk of developing dental fluorosis. ${ }^{12}$

Considering the narrow "dose gap" between caries depletion advantages and fluoride adverse toxic effects, public health officials have limited fluoride concentrations in

\section{(c) 2020. European Journal of Dentistry.}

This is an open access article published by Thieme under the terms of the Creative Commons Attribution-NonDerivative-NonCommercial-License, permitting copying and reproduction so long as the original work is given appropriate credit. Contents may not be used for commercial purposes, or adapted, remixed, transformed or built upon. (https://creativecommons.org/licenses/by-nc-nd/4.0/)

Thieme Medical and Scientific Publishers Pvt. Ltd., A-12, 2nd Floor, Sector 2, Noida-201301 UP, India 
over-the-counter toothpastes to within 1,000 and 1,500 ppm. As for children younger than 6 years, this dose is even lower and considered less than the effective remineralization level of early carious regions. ${ }^{13}$ Evidently, the need for newer remineralization agents arises to complement to fluoride effect and to enhance its remineralization efficacy on the carious lesions. ${ }^{14}$ The actual tendencies aim to shift toward natural products to allay the safety concerns, thanks to their fewer side effects, ${ }^{15}$ and their effectiveness in the field of dentistry.

Numerous medicinal plant extracts have shown the ability to inhibit the formation of dental biofilms by reducing pathogen adhesion to tooth surface, a primary event in caries formation. ${ }^{16}$ Among all the different herbs used in the dental field, modern science corroborates Aloe vera (AV)'s antimicrobial properties. Studies suggest that AV (Aloe barbadensis) extract is appropriate for treating gingivitis and oral infections since it inhibits plaque formation and bacterial growth. ${ }^{17,18}$

A cactus-like plant, AV encompasses 360 species containing 75 active ingredients such as vitamins, enzymes, minerals, sugars, lignins, saponins, salicylic acids, and amino acids. ${ }^{19}$ AV's medicinal effect in vitro or on animal models has demonstrated anti-inflammatory, antiarthritic, antibacterial effects, immune-boosting, and hypoglycemic properties. ${ }^{20}$ Other studies have evaluated AV's effect on systemic disease, cancers, regulation of blood glucose levels, and wound and infection healing. ${ }^{19}$

Several published studies have further reported the use of AV in dentistry for various purposes such as its antiseptic effect on Candida albicans and aphthous stomatitis treatment, ${ }^{21}$ as well as its use as an ingredient in toothpastes and mouthwashes for the treatment of gingivitis. ${ }^{22-24}$ However, there are only few other studies about the particular effect of $\mathrm{AV}$ in the remineralization of early carious lesions. ${ }^{25}$

This study intends to evaluate the in vitro effects of the local application of AV gel to demineralized teeth and, ultimately, observe the possibility of using AV gel or an AV-based toothpaste as an adjuvant substance to fluoride toothpastes.

\section{Materials and Methods}

In this study, 40 sound permanent premolar and molar teeth extracted for diverse purposes were collected from the Department of Oral Surgery, Faculty of Dental Medicine, Saint Joseph University of Beirut. The study was approved by the university ethics committee.

The 40 teeth were cleansed of soft tissue debris and inspected for cracks, hypoplasia, caries, and white spot lesions, then coated with a nail varnish, leaving a narrow $4 \mathrm{~mm} \times 1 \mathrm{~mm}$ wide window on the intact surface of the buccal enamel. They were then immersed in the demineralizing solution for 4 days to produce lesions in the window area following the published protocol of Kumar et al. ${ }^{26}$ The demineralizing solution contained $2.2 \mathrm{mM} \mathrm{CaCl}, 2.2 \mathrm{mM}$ $\mathrm{NaH}_{2} \mathrm{PO}_{4}$, and $50 \mathrm{mM}$ acetic acid and had a pH adjusted to 4.4 at $37^{\circ} \mathrm{C}$ with $1 \mathrm{M} \mathrm{KOH}$. Each tooth was then sectioned buccolingually, thus creating two sections from each tooth to measure the lesion depth. Eleven hemisections were very thin and were excluded from the study because of technical problems arising while using the scanning electron microscope (SEM).

The prepared specimens were then gold sputtered and observed under the SEM at a magnification of 1,000. Energy dispersive X-ray (EDX) analysis was performed to assess the mineral content in the samples. SEM was used for the structural analysis, whereas EDX was used for the elemental analysis.

\section{Test Groups}

The sections were randomly assigned to four treatment groups as follows. Group A, a positive control group, included 14 hemisections treated with a 1,450-ppm fluoride toothpaste (Colgate Total, Bangkok, Thailand). Group B, an experimental group, comprised 14 hemisections treated using an AV 1,000-ppm fluoride toothpaste (Dr Organic Aloe vera toothpaste, Holland \& Barret). The experimental group C consisted of 15 hemisections treated using an AV nonfluoridated toothpaste (Aloe Dent whitening, Holland and Barret). As to group D, it comprised 14 experimental hemisections coated with an AV leaf gel.

Toothpaste supernatants in groups A, B, and C were prepared by suspending $10 \mathrm{~g}$ of the respective toothpaste in $30 \mathrm{~mL}$ of deionized water to achieve a ratio of 1:3 (toothpaste:deionized water) ${ }^{26}$ The suspensions were thoroughly stirred and mechanically shaken for 1 minute.

For group D, a sufficient amount of gel from the AV leaf was deposited in a sterile container, stored at $4^{\circ} \mathrm{C}$ until application time and changed daily. The gel's chemical analysis demonstrated the presence of $98.5 \%$ of water. The remaining parts are solid matter, compounds comprising vitamins, minerals, enzymes, polysaccharides, phenolic compounds, and organic acids in variable proportions (-Fig. 1).

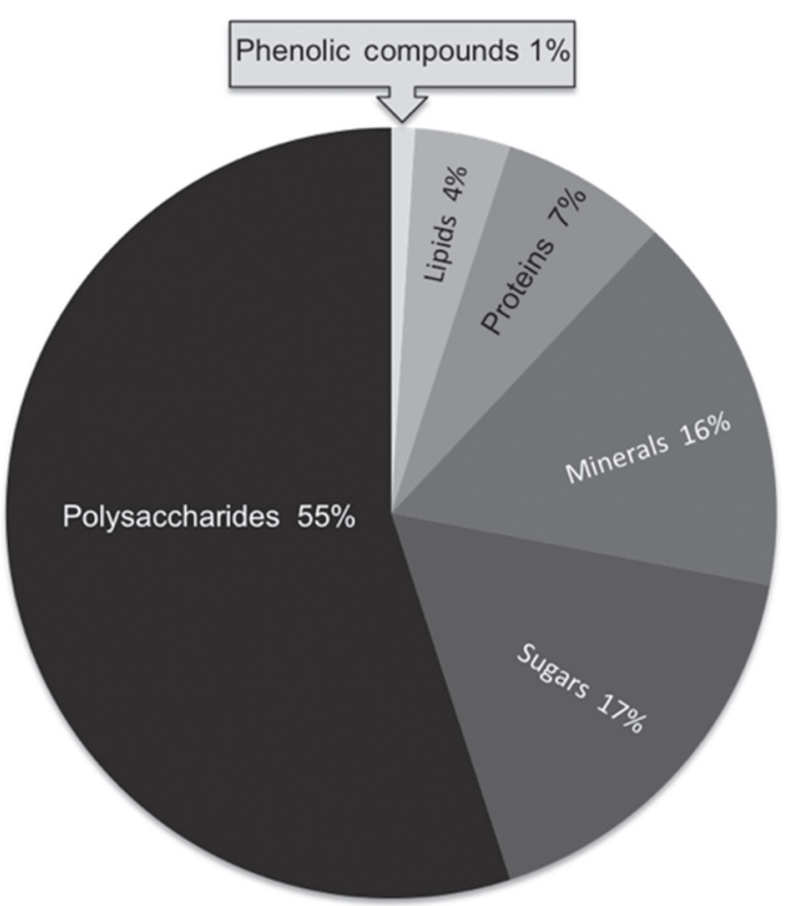

Fig. 1 Composition of the solid matter of the Aloe vera gel. 
Each group was treated with their, respectively, assigned toothpaste for 10 days, twice daily for 3 minutes, at $10 \mathrm{AM}$ and 8 PM while placed on an orbital shaker. For the remaining time during these 10 days, the sections were immersed in the already prepared remineralizing solution consisting of $1.5 \mathrm{mM}$ of $\mathrm{CaCl}_{2}, 0.9 \mathrm{mM}$ of $\mathrm{NaH}_{2} \mathrm{PO}_{4}$, and $0.15 \mathrm{M}$ of $\mathrm{KCl}$ with a $\mathrm{pH}$ adjusted to 7 at $37^{\circ} \mathrm{C}$. SEM-EDX was conducted after the remineralization. The calcium (Ca) and phosphorus (P) mean value and standard deviation as well as the $\mathrm{Ca}: \mathrm{P}$ ratio were calculated, then compared between the groups.

\section{Statistical Analysis}

The Statistical Package Software for the Social Sciences (SPSS for Windows, Version 25.0, Chicago, Illinois, United States) was used to perform statistical data analysis. The $\alpha$ error was set at 0.05 . The mean percentage and standard deviation of each group were subsequently calculated.

Kolmogorov-Smirnov's tests were conducted to verify the distribution normality of quantitative variables. Repeatedmeasures analyses of variance followed by univariate analyses and Bonferroni's multiple comparisons tests were performed to compare the Ca:P ratio within time among toothpaste groups.

\section{Results}

The mean and standard deviation of the Ca:P ratio for the four toothpastes are presented in - Table 1, and the diagrams showing the weight percentage of $\mathrm{Ca}$ and $\mathrm{P}$ ions before and after remineralization are presented in -Figs. 2 and $\mathbf{3}$.

\section{Before and After Remineralization}

This study showed that the average ratio as well as the Ca percentage significantly increased after mineralization in the groups treated with the AV 1,000-ppm fluoridated toothpaste $(p$-value $=0.001), 1,450-p p m$ fluoride toothpaste $(p$-value $<0.001)$, and AV gel $(-p$-value $=0.002)$. Although the average ratio increased in the fluoride-free AV toothpaste group, the increase was close to the significance $(p$-value $=0.054)$.

\section{Comparison between Groups}

After demineralization, the difference was not significant between the four groups $(p$-value $=0.301)$. However,

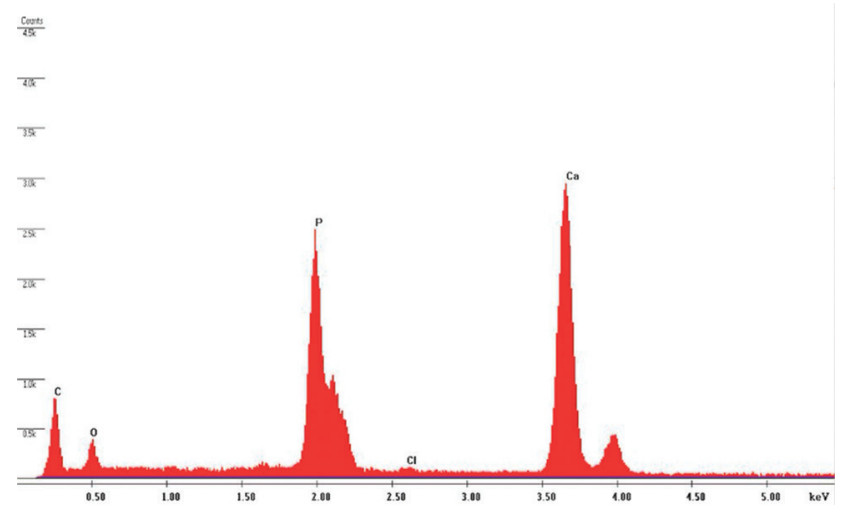

Fig. 2 Energy dispersive X-ray diagram showing wt\% of Ca after demineralization.

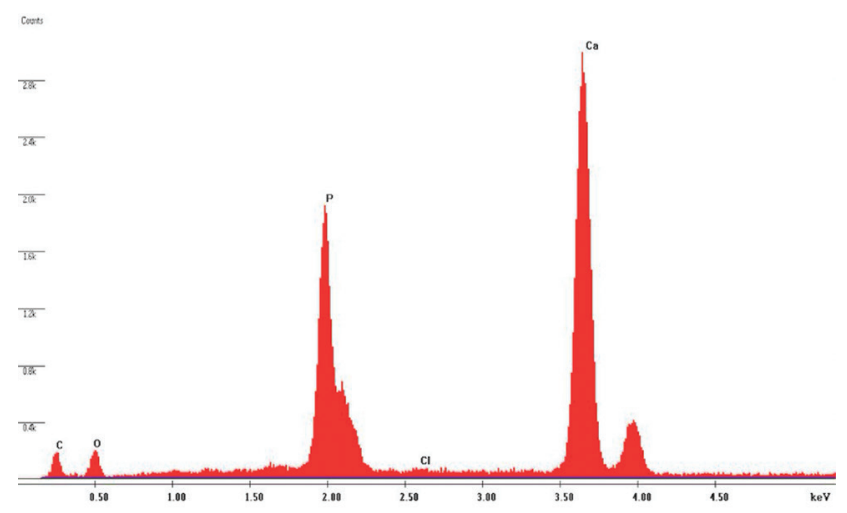

Fig. 3 Energy dispersive X-ray diagram showing wt\% of Ca after remineralization.

Table 1 Calcium-to-phosphorus ratio before and after respective treatment

\begin{tabular}{|c|c|c|c|c|c|}
\hline & Groups & Mean & $\begin{array}{l}\text { Standard } \\
\text { deviation }\end{array}$ & $N$ & $p$-Value \\
\hline \multirow[t]{4}{*}{$\begin{array}{l}\text { Calcium/phosphorus } \\
\text { ratio before }\end{array}$} & $\begin{array}{l}\text { Aloe vera and fluoride } \\
\text { toothpaste } 1,000 \mathrm{ppm}\end{array}$ & 1.800 & 0.1840 & 14 & \\
\hline & $\begin{array}{l}\text { Nonfluoridated Aloe vera } \\
\text { toothpaste }\end{array}$ & 1.687 & 0.1356 & 15 & \\
\hline & $\begin{array}{l}\text { Fluoridated toothpaste } \\
1,450 \mathrm{ppm}\end{array}$ & 1.700 & 0.1664 & 14 & \\
\hline & Aloe vera gel & 1.735 & 0.2039 & 14 & \\
\hline \multirow[t]{4}{*}{$\begin{array}{l}\text { Calcium/phosphorus } \\
\text { ratio after }\end{array}$} & $\begin{array}{l}\text { Aloe vera and fluoride } \\
\text { toothpaste } 1,000 \mathrm{ppm}\end{array}$ & 2.043 & 0.1828 & 14 & 0.001 \\
\hline & $\begin{array}{l}\text { Nonfluoridated Aloe vera } \\
\text { toothpaste }\end{array}$ & 1.820 & 0.2426 & 15 & 0.054 \\
\hline & $\begin{array}{l}\text { Fluoridated toothpaste } \\
1,450 \mathrm{ppm}\end{array}$ & 2.057 & 0.2027 & 14 & $<0.001$ \\
\hline & Aloe vera gel & 1.950 & 0.2226 & 14 & 0.002 \\
\hline
\end{tabular}

Note: $N$, number of elements in the sample. 
following remineralization, the mean ratio was significantly different among the groups. It was smaller in the AV fluoride-free group ( $p$-value $=0.026$ ), whereas the difference was not significant between the 1,000-ppm fluoridated AV, AV gel, and 1,450-ppm fluoride toothpaste ( $p$-value $>0.05$ )

\section{Discussion}

AV nonfluoridated toothpaste induces a remineralization lower than that obtained from the 1,450-ppm fluoride toothpaste, but the addition of AV to a 1,000-ppm fluoride toothpaste serves as a remineralization adjuvant. The AV gel offers remineralization similar to that induced by a $1,450-\mathrm{ppm}$ fluoride toothpaste. Even under fluoride-free conditions, the AV gel acts as a dental remineralizing booster.

The protocol of this study was developed to reduce bias: SEM allows the evaluation of morphological variations between treated and untreated surfaces. However, one key drawback inherent in SEM's exclusive use is that it does not assess the treated and untreated surfaces' chemical composition as well as their mineral loss and gain. To overcome this problem, EDX tooth analysis was used in conjunction with SEM analysis to obtain the Ca and P percentage in the teeth before and after remineralization. Shaik et al, Chaudhary et al, and Sriamporn et al also used SEM-EDX in their in vitro studies..$^{27-29}$

The study's protocol conditions were most compatible with the oral conditions. The remineralizing solution used is the closest in its composition to mineral ions and in its supersaturation to natural saliva as reported first by ten Cate and Duijsters. ${ }^{30}$

A $4 \mathrm{~mm} \times 1 \mathrm{~mm}$-wide window was created on the buccal surface of the enamel to standardize the window size in all specimens, produce lesions only in the area of the window, and limit the area of paste application according to Shirahatti et al and Vashisht et al. ${ }^{31,32}$ The teeth were immersed in a demineralization solution for 4 days, and then evaluated for any mineral content loss (\% by weight) using SEM-EDX after sectioning them in halves.

A 10-day pH-cycling period was followed, which is sufficient to create changes in lesions without the risk of damaging thin enamel specimens. ${ }^{33}$ The solutions used were changed regularly to avoid solution saturation or exhaustion due to the accumulation of the enamel dissolution products. ${ }^{30}$ Specimens in each group were shaken during the 3-minute application of the respective treatment to prevent the formation of deeper lesions and greater mineral loss compared with unstirred systems. ${ }^{34}$

Our in vitro study shows that remineralization has been achieved across all groups, with the highest rate of remineralization achieved when treatment was performed with the AV gel, followed by the AV 1,000-ppm fluoride toothpaste both at a level similar to that of a 1,450-ppm fluoride toothpaste. In the literature review on natural products used for tooth decay prevention, the role of polyphenols in dental remineralization has systematically been preeminent. ${ }^{35}$ In fact, the gel alone is composed of $98.5 \%$ of water. The remaining components represent a mixture of vitamins, minerals, enzymes, polysaccharides, phenolic compounds, and organic acids in different proportions. Polyphenols, including anthraquinones, seem to be the essential active chemical component responsible for the AV gel's capacity in inducing remineralization.

On the contrary, the remineralization effect of the AV fluoride-free toothpaste is less than the other three groups, including the AV gel group. This can be explained by the concentration of the active components, present in lesser amounts in the toothpaste while they are more saturated in the gel or due to the industrialization process.

Since the remineralizing effect of the AV toothpaste and AV gel was not previously developed in the literature, the claim can be made that the study results are of a pioneering nature; hence, they are not comparable to those of other studies on AV dental use. Thus, a comparison of the results with other in vitro studies experimenting the remineralization action of new nonfluoridated remineralization products will be followed in this discussion, which also used the SEMEDX technique to measure changes in Ca and P concentrations in the carious lesion.

Casein phosphopeptide-amorphous calcium phosphate, known as CPP-ACP, plays a role in preventing demineralization and improving remineralization. ${ }^{36}$ Hegde and Moany (2012) aimed to evaluate CPP-ACP potential for remineralization on enamel lesions over time. A pH cycling of 7, 14, 21,28 , and 35 days followed a 5 -day demineralization procedure. ${ }^{37}$ The collected specimens were then analyzed by SEMEDX and the Ca:P ratio was calculated. The results showed an average Ca:P ratio of 1.5 prior to treatment, which aligns with that obtained in this study. After 14 days of remineralization by CPP-ACP, the Ca:P ratio was 1.7, and it is only after 35 days that the Ca:P ratio reached 1.9 , a value reached by treatment with AV gel after 10 days only. In addition, treatment with $\mathrm{AV}$ toothpaste and 1,000-ppm fluoride has a remineralizing efficacy (2.0043) greater than that with CPP-ACP even after 35 days of application (1.93). Also, among the natural products that have a role in dental remineralization, we cite the Galla chinensis extract (GCE).

Cheng et $\mathrm{al}^{38}$ in their study on the effect of GCE on the remineralization of the enamel surface in vitro used bovine teeth to which a 12-day $\mathrm{pH}$ cycling was performed to try to remineralize the carious lesions using four different types of products including fluorine, GCE, gallic acid, and demineralized water as a control group. The enamel specimens were analyzed using a SEM-EDX device. The percentage of Ca obtained in the NaF group (30.88\%) is lower than that obtained in our study (41.47\%) in the similar group; however, the Ca:P ratio of 2.12 is comparable to the ratio obtained in the present study (2.043). These differences can be explained not only by the use of different protocols and demineralization models in the two experiments but also by the different EDX calibration procedures and the number of measurements taken for each sample. In addition, different counting rates, dead times, measurement times, and measurement windows could explain these differences. Taking into account the comparability of the Ca:P ratios, this can be extrapolated to compare the effectiveness of remineralization between AV and GCE: Cheng et al 
obtained a ratio of 1.91 after treatment with GCE, whereas in our study, we obtained 1.950 after treatment with AV gel and 2.043 for a toothpaste based on AV fluorinated at 1,000 $\mathrm{ppm}$. This result is favorable to the gel of AV, which, according to the results obtained, has remineralizing properties on the surface better than those found with the extract of GCE.

Also, Zhang et $\mathrm{al}^{39}$ in 2009 performed a comparative study on the remineralizing power in vitro of GCE and a fluoride toothpaste. The measurement technique used is similar to that used in our study, SEM-EDX. The percentage by mass of Ca (46.73\%) and P (19.14\%) after treatment with fluoride toothpaste is consistent with the results obtained in our study with fluoride toothpaste. Although the percentage of Ca in the GCE group increased statistically significantly after treatment, the ratio obtained (1.52) remains lower than that obtained with AV gel (1.950).

\section{Conclusion}

Within the limitations of this study, the remineralization induced by $1,000-p p m$ fluoridated AV toothpaste and AV gel showed a similar rate to that of the 1,450-ppm fluoride toothpaste. This study may be considered a pivotal cornerstone for future studies targeted at explaining the process by which AV gel transports Ca ions to the tooth surface.

However, chemical characterization and standardization of the use of AV, as well as in vivo studies using various measurement techniques, are required prior to further implementation in trials and clinical use.

\section{Funding}

None.

\section{Conflict of Interest}

None declared.

\section{Acknowledgments}

This article and the research behind it would not have been possible without the financial and moral support of the Saint Joseph University of Beirut, through its research council. We thank the Lebanese University for providing some of the equipment needed, our colleague Dr. Nada Osta for the statistical guidance, as well as Dr. Roland Habchi, Jamil Ali, and Charbel Mansour for the laboratory assistance.

\section{References}

1 Featherstone JDB, Chaffee BW. The evidence for caries management by risk assessment (CAMBRA®). Adv Dent Res 2018; 29(1):9-14

2 Benson PE, Parkin N, Dyer F, Millett DT, Furness S, Germain P. Fluorides for the prevention of early tooth decay (demineralised white lesions) during fixed brace treatment. Cochrane Database Syst Rev 2013;12(12):CD003809

3 Marinho VC, Higgins JP, Sheiham A, Logan S. Fluoride toothpastes for preventing dental caries in children and adolescents. Cochrane Database Syst Rev 2003;3(1):CD002278
4 Marinho VC, Worthington HV, Walsh T, Chong LY. Fluoride gels for preventing dental caries in children and adolescents. Cochrane Database Syst Rev 2015;6(6):CD002280

5 Marinho VC, Chong LY, Worthington HV, Walsh T. Fluoride mouthrinses for preventing dental caries in children and adolescents. Cochrane Database Syst Rev 2016;7:CD002284

6 Shahid M. Regular supervised fluoride mouthrinse use by children and adolescents associated with caries reduction. Evid Based Dent 2017;18(1):11-12

7 Agustsdottir H, Gudmundsdottir H, Eggertsson H, et al. Caries prevalence of permanent teeth: a national survey of children in Iceland using ICDAS. Community Dent Oral Epidemiol 2010;38(4):299-309

8 AIHW, Dental and Oral Health Overview. Australian Welfare 2017. Australian Welfare Series No 13. AUS 214. Canberra: AIHW; 2018

9 Dye BA, Vargas CM, Fryar CD, Ramos-Gomez F, Isman R. Oral health status of children in Los Angeles County and in the United States, 1999-2004. Community Dent Oral Epidemiol 2017;45(2):135-144

10 Haugejorden O, Birkeland JM. Analysis of the ups and downs of caries experience among Norwegian children aged five years between 1997 and 2003. Acta Odontol Scand 2005;63(2):115-122

11 Grandjean P, Landrigan PJ. Neurobehavioural effects of developmental toxicity. Lancet Neurol 2014;13(3):330-338

12 Zohoori FV, Maguire A. Are there good reasons for fluoride labelling of food and drink?. Br Dent J 2018;224(4):215-217 doi:10.1038/sj.bdj.2018.123

13 Philip N. State of the art enamel remineralization systems: the next frontier in caries management. Caries Res 2019;53(3):284-295

14 Lynch RJ, Smith SR. Remineralization agents - new and effective or just marketing hype. ? Adv Dent Res 2012;24(2):63-67

15 Taheri JB, Azimi S, Rafieian N, Zanjani HA. Herbs in dentistry. Int Dent J 2011;61(6):287-296

16 Jain I, Jain P, Bisht D, Sharma A, Srivastava B, Gupta N. Use of traditional Indian plants in the inhibition of caries-causing bacteria-Streptococcus mutans. Braz Dent J 2015;26(2):110-115

17 Bhati N, Jaidka S, Somani R. Evaluation of antimicrobial efficacy of Aloe vera and Meswak containing dentifrices with fluoridated dentifrice: An in vivo study. J Int Soc Prev Community Dent 2015;5(5):394-399

18 Dhingra K. Aloe vera herbal dentifrices for plaque and gingivitis control: A systematic review. Oral Dis 2014;20(3):254-267

19 Vogler BK, Ernst E. Aloe vera: a systematic review of its clinical effectiveness. Br J Gen Pract 1999;49(447):823-828

20 Rams TE, Slots J. Local delivery of antimicrobial agents in the periodontal pocket. Periodontol 2000 1996;10:139-159

21 Babaee N, Zabihi E, Mohseni S, Moghadamnia AA. Evaluation of the therapeutic effects of Aloe vera gel on minor recurrent aphthous stomatitis. Dent Res J (Isfahan) 2012;9(4):381-385

22 Pradeep AR, Agarwal E, Naik SB. Clinical and microbiologic effects of commercially available dentifrice containing Aloe vera: a randomized controlled clinical trial. J Periodontol 2012;83(6):797-804

23 Chandrahas B, Jayakumar A, Naveen A, Butchibabu K, Reddy PK, Muralikrishna T. A randomized, double-blind clinical study to assess the antiplaque and antigingivitis efficacy of Aloe vera mouth rinse. J Indian Soc Periodontol 2012;16(4):543-548

24 Namiranian H, Serino G. The effect of a toothpaste containing aloe vera on established gingivitis. Swed Dent J 2012;36(4):179-185

25 Silva T, Fonseca F, Sales A, Holleben P, Valera M, Araújo M. Effects of fluoride andAloe veratooth gel in artificial white spot lesionsin vitro. RGO Rev Gaúcha Odontol 2016;64(1):56-61 
26 Kumar VL, Itthagarun A, King NM. The effect of casein phosphopeptide-amorphous calcium phosphate on remineralization of artificial caries-like lesions: An in vitro study. Aust Dent J 2008;53(1):34-40

27 Shaik ZA, Rambabu T, Sajjan G, et al. Quantitative analysis of remineralization of artificial carious lesions with commercially available newer remineralizing agents using SEM-EDXin vitro study" J Clin Diagn Res 2017;11(4):ZC20-ZC23

28 Chaudhary I, M Tripathi A, Yadav G, Saha S. Effect of casein phosphopeptide-amorphous calcium phosphate and calcium sodium phosphosilicate on artificial carious lesions: an in vitro study. Int J Clin Pediatr Dent 2017;10(3):261-266

29 Sriamporn T, Kraisintu P, See LP, Swasdison S, Klaisiri A, Thamrongananskul $\mathrm{N}$. Effect of different neutralizing agents on feldspathic porcelain etched by hydrofluoric acid. Eur J Dent 2019;13(1):75-81

30 ten Cate JM, Duijsters PP. Alternating demineralization and remineralization of artificial enamel lesions. Caries Res 1982;16(3):201-210

31 Shirahatti RV, Ankola AV, Nagesh L, Hallikerimath S. The effects of three different pastes on enamel caries formation and lesion depth progression - an in vitro study. J Oral Health Comm Dent 2007;1(1):1-6

32 Vashisht R, Kumar A, Indira R, Srinivasan MR, Ramachandran S. Remineralization of early enamel lesions using casein phosphopeptide amorphous calcium phosphate: an ex-vivo study. Contemp Clin Dent 2010;1(4):210-213

33 Rehder-Neto FC, Menezes M, Chimello TD, Serra MC. Development of caries-like lesions in human and bovine dentin compared to natural caries. Rev Odontol UNESP 2010; 39(3):163-168

34 Ruben J, Arends J, Christoffersen J. The effect of window width on the demineralization of human dentine and enamel. Caries Res 1999;33(3):214-219

35 Cheng L, Li J, He L, Zhou X. Natural products and caries prevention. Caries Res 2015;49(Suppl 1) :38-45

36 Reynolds EC. Calcium phosphate-based remineralization systems: Scientific evidence? Aust Dent J 2008;53(3):268-273

37 Hegde MN, Moany A. Remineralization of enamel subsurface lesions with casein phosphopeptide-amorphous calcium phosphate: A quantitative energy dispersive X-ray analysis using scanning electron microscopy: An in vitro study. J Conserv Dent 2012;15(1):61-67

38 Cheng L, Li J, Hao Y, Zhou X. Effect of compounds of Galla chinensis on remineralization of enamel surface in vitro. Arch Oral Biol 2010;55(6):435-440

39 Zhang LL, Li JY, Zhou XD, Cui FZ, Wei L. Chemical and crystallographic study of remineralized surface on initial carious enamel treated with Galla chinensis. Scanning 2009;31(6):236-245 